\title{
Comparison of Clinical and Inflammatory Parameters in Dogs with Pyometra Before and After Ovariohysterectomy
}

\section{Soomin Ahn}

Gyeongsang National University

HyunJung Han

Konkuk Univerisity

Jinho Park

Jeonbuk National University

\section{Sang-Ki Kim}

Kongju National University

\section{Dong-In Jung}

Gyeongsang National University

Dohyeon Yu ( $\nabla$ yudh@gnu.ac.kr)

Gyeongsang National University https://orcid.org/0000-0001-7645-6926

\section{Research article}

Keywords: Biomarker, Sepsis, Cytokine, Ovariohysterectomy, Pyometra

Posted Date: January 13th, 2021

DOI: https://doi.org/10.21203/rs.3.rs-143024/v1

License: (c) (i) This work is licensed under a Creative Commons Attribution 4.0 International License. Read Full License 


\section{Abstract}

Background: this study aimed to identify potential biomarkers for the screening and therapeutic monitoring of sepsis in canine pyometra and correlations with clinical parameters. Samples were collected from a total of 90 dogs with pyometra and 26 healthy female controls. The levels of inflammatory biomarkers and clinical parameters recorded in the dogs with pyometra at presentation were compared with those in the healthy subjects. In addition, consecutive samples from 22 dogs with surgically corrected pyometra and nine healthy controls, were compared before and after ovariohysterectomy.

Results: significant leucocytosis, anaemia, hyperglobulinaemia, hypoalbuminaemia, and elevated activities of the alanine aminotransferase and alkaline phosphatase (ALP) enzymes, were observed in the dogs with pyometra at presentation. Moreover, the concentrations of acute inflammatory proteins of C-reactive protein (CRP) and serum amyloid A (SAA), as well as those of cell-free DNA (cfDNA), were significantly higher in the dogs with pyometra. cfDNA was the most sensitive biomarker for systemic inflammation, based on the receiver operating characteristic curve analysis (area under the curve = 0.959). After surgical removal of the inflamed uterus, leucocyte and red blood cell counts, cholesterol, albumin, globulin levels, and the ALP activity significantly decreased. The levels of inflammatory parameters such as interleukin-6 (IL-6), highmobility group box 1 (HMGB1), and procalcitonin (PCT) also significantly decreased after surgical treatment.

Conclusions: these findings indicate that cfDNA, CRP, and SAA have the potential to be used as clinical biomarkers for screening canine sepsis, whereas PCT, IL-6, and HMGB1 may be useful biomarkers for the therapeutic monitoring of canine sepsis.

\section{Background}

Pyometra is characterised by the accumulation of uterine pus and may be compounded by opportunistic bacterial infections. Pyometra can result in systemic inflammatory response syndrome (SIRS), as well as sepsis and organ damage, and therefore, dogs with pyometra are used as a natural model of sepsis [1]. Surgical treatment by ovariohysterectomy (OHE) removes the source of inflammation. It could thus be used as a model for therapeutic monitoring of canine sepsis and to identify diagnostic biomarkers to better understand the pathophysiology of both human and veterinary sepsis.

Several biomarkers pertaining to canine sepsis have been reported from studies of different diseases, including pyometra [2-8]. These biomarkers include cytokines and chemokines [4, 5, 9, 10], acute-phase proteins (APPs) [11], and damageassociated molecular patterns [12]. However, studies comparing levels of biomarkers before and after surgical correction of pyometra are limited.

The objective of this study was to identify potential biomarkers for screening and therapeutic monitoring of naturally occurring canine sepsis caused by pyometra, based on the differences in clinical and inflammatory parameters between female dogs with pyometra and healthy ones and on the changes in these parameters after surgical correction of pyometra.

\section{Results}

\subsection{Classification and characterisation of dogs}

The 90 dogs with pyometra enrolled in this study included 17 different breeds as follows: the Maltese $(n=24)$, Shih Tzu $(n=$ $11)$, Yorkshire Terrier $(n=10)$, Miniature Poodle $(n=9)$, Miniature Schnauzer $(n=7)$, Pomeranian $(n=7)$, mixed-breed dogs $(n$ $=6)$, the Miniature Pinscher $(n=4)$, Dachshund ( $n=2)$, French Bulldog $(n=2)$, Jindo $(n=2)$, and one each of the Chow-Chow, Cocker Spaniel, Golden Retriever, Pointer, Pungsan, and Shiba Inu. The mean age of the dogs with pyometra was nine years (range: 1-15 years), and the 26 healthy controls, consisting of 15 different breeds, had a mean age of 5 years (range: 110 years). The difference in the mean ages was significant $(P<0.01)$. All diseased dogs had open cervix-type pyometra and survived to discharge. 


\subsection{Comparison of clinical data and inflammatory parameters between pyometra and healthy dogs}

The clinical data, including haematologic and biochemical data, showed significant differences between the subjects with pyometra and healthy controls (Table 1). Among the haematologic variables, the mean leukocyte, neutrophil, and monocyte counts were significantly higher $(P<0.01)$, while erythrocyte counts, haematocrit levels, and haemoglobin concentrations were significantly lower $(P<0.01)$ in the dogs with pyometra than in the healthy subjects. The total protein, globulin, alanine aminotransferase (ALT; $P<0.05$ ), and alkaline phosphatase (ALP; $P<0.01$ ) concentrations were significantly higher in the dogs with pyometra than in the healthy ones.

The concentrations of inflammatory parameters in the subjects with pyometra and healthy dogs are presented in Fig. 1. In the dogs with pyometra, the serum CRP, SAA, and cfDNA concentrations were significantly higher $(P<0.01)$ than those in the healthy subjects. However, the IL-6, PCT, and HMGB1 concentrations did not show significant differences.

Using ROC curve analysis to evaluate the usefulness of each biomarker for discrimination between the subjects with pyometra and the healthy ones (Fig. 2), cfDNA was found to be the best predictive biomarker (area under the curve $=0.959$ ), with a combined sensitivity of $97 \%$ and a specificity of $80 \%$ for differentiating dogs with pyometra, followed by plasma CRP, with a combined sensitivity of $88 \%$ and a specificity of $100 \%$.

In the dogs with pyometra, the cfDNA concentrations were correlated with the white blood cell (WBC) and neutrophil counts and the globulin concentrations $(r=0.46,0.47$, and 0.44 , respectively; $P<0.01)$. There also was a moderate correlation between the IL- 6 concentration and total protein content $(r=0.88, P<0.01)$. Furthermore, PCT was significantly correlated with haematocrit, monocytes, blood urea nitrogen (BUN), albumin, globulin, and ALP ( $r=-0.33,0.38,0.41,-0.37,0.33$, and 0.34 , respectively; $P<0.05)$ (Table 2$)$.

Additional categories were assessed to obtain more detail about the differences in inflammatory parameters between subgroups of the dogs with pyometra that were clinically worse (above or below the reference intervals for clinicopathologic parameters) (Table 3). Among inflammatory parameters, differences were detected in cfDNA and CRP, and both biomarkers were associated with several significant inflammation-related clinical parameters

\subsection{Comparison of clinical data and inflammatory parameters depending on surgical correction}

After surgical correction, dramatic changes were observed in the clinical data (Table 4). In the dogs with pyometra, the postOHE leucocyte and neutrophil counts were significantly higher $(P<0.01)$, whereas erythrocytes, haematocrit, and haemoglobin were significantly lower $(P<0.01)$ than the respective pre-OHE levels. In the biochemical panel, the post-OHE total protein, globulin, cholesterol, $\mathrm{pH}$, and potassium concentration values were significantly lower $(P<0.01)$ than the preOHE ones, as were the glucose, BUN, creatinine, albumin, ALP, and ionised calcium concentrations $(P<0.05)$.

There were no differences between the pre- and post-OHE values of CRP, SAA, and cfDNA in the dogs with pyometra (Fig. 3). However, the concentrations of IL-6, PCT, and HMGB1 significantly decreased after OHE $(P<0.05)$.

\section{Discussion}

In this study, we investigated the clinical data and inflammatory parameters in dogs with pyometra at presentation, before and after surgical correction. Increases in the WBC counts, ALT and ALP activities, and concentrations of cholesterol and amylase and decreases in the RBC counts, haematocrit, hyperglobulinaemia, and hypoalbuminaemia were statistically significant in the dogs with pyometra compared to healthy dogs. Furthermore, significantly increased CRP, SAA, and cfDNA concentrations were found in dogs with pyometra compared to healthy dogs. After surgical correction of pyometra via OHE, 
the WBC and RBC counts, cholesterol, albumin, globulin concentrations, and ALP activity, as well as the IL-6, HMGB1, and PCT levels significantly decreased compared to pre-OHE.

In the dogs with pyometra, leucocytes and especially neutrophils and monocytes were significantly increased, whereas the RBC counts and haematocrit were decreased. Myeloid hyperplasia, especially neutrophilia, contributes to leucocytosis, and decreased iron utilisation in myeloid cells of the bone marrow by the APPs lactoferrin and hepcidin in response to systemic inflammation can reduce erythropoiesis [13-15]. Hyperproteinaemia, hyperglobulinaemia, and hypoalbuminaemia were also statistically significant in the dogs with pyometra vs. healthy controls, owing to an increased synthesis of APPs and antibodies in response to bacterial infection and inflammation. Decreased albumin levels may suggest a negative APP function [16] and are commonly associated with an inflammatory disease.

Organ damage is common during systemic inflammation in dogs [17]. There were significant increases in ALT, ALP activities, and cholesterol concentration in the subjects with pyometra in this study. Increased liver enzyme activities and cholesterol concentrations were also observed in intrahepatic cholestasis, which is associated with endotoxaemia and hepatocellular damage caused by diminished circulation and cellular hypoxia [16]. Renal injuries could be found in canine endotoxemia [18], and increases in creatinine concentrations, although not statistically significant, were found in this study. A decreased glomerular filtration rate due to endotoxaemia, may contribute to increases in amylase and lipase levels. Endotoxaemia may contribute to renal injury, but disease severity may affect the results. All dogs with pyometra survived in this study, which may indicate a lower disease severity, and therefore renal damage that might be statistically insignificant. Dogs with vaginal discharge were selected in this study, which could help with an early diagnosis before septic insult. Surgical correction decreased the RBC indices, total protein, albumin, and globulin levels, while increasing the sodium and chloride levels. Fluid administration during a surgical procedure may result in haemodilution and contribute to changes in electrolytes.

The CRP and SAA concentrations were significantly higher in the dogs with pyometra than in the healthy ones. CRP and SAA are the major APPs in dogs, and these results are consistent with those of previous reports on dogs with SIRS and pyometra [3] or chronic inflammation [19-21]. We also found a strong positive correlation between CRP and SAA. Thus, combined monitoring of the CRP and SAA biomarkers may be clinically advantageous for diagnosing inflammation. However, cfDNA was the most discriminative among the inflammatory parameters tested, based on the ROC curve analysis. Recent studies have suggested that the presence of cfDNA is due to necrosis, apoptosis, and the release of neutrophil extracellular traps (NETs), which are networks of extracellular fibres, primarily composed of DNA from neutrophils and binding pathogens. These fibres are released as a result of an innate immune mechanism initiated by neutrophils [22, 23], and thus, higher concentrations of cfDNA in dogs with pyometra may be due to tissue damage, resulting from systemic inflammation and NET formation. Besides, we found that the cfDNA concentrations, unlike the CRP and SAA levels, were correlated with the WBC counts, one of the SIRS criteria. The elevation of WBCs, especially neutrophils, is a typical sign of inflammation, suggesting that serum cfDNA concentrations may reflect inflammatory processes in dogs with sepsis.

In the dogs with pyometra, abnormal clinical parameters were strongly correlated with the cfDNA, CRP, and SAA concentrations. Correlations between the concentrations of these parameters and disease severity have been previously reported for CRP, SAA [24], and cfDNA [25]; however, there were no significant differences in these parameters before and after surgical correction. Moreover, the CRP level was the only inflammatory parameter that increased after surgery in healthy dogs, consistently with previous studies $[12,19,26]$. Surgical insult such as a laparotomy could affect the CRP concentration, even in healthy dogs, making CRP an unspecific biomarker for therapeutic monitoring. A more representative controlled study should be performed in the future to clarify the significance of this parameter.

When the infection source is removed, the concentrations of several biomarkers should decrease relative to those of endotoxins. Thus, we considered changes in the concentrations of inflammatory parameters as biomarkers for therapeutic monitoring. The study showed that most dogs with pyometra had lower concentrations of all cytokines following surgical treatment. These findings agree with the results of the comparison between dogs with pyometra and healthy ones. Although 
not all inflammatory parameters were fully accounted for by the treatment effects, IL-6, HMGB1, and PCT emerged as potentially relevant biomarkers for therapeutic monitoring. The baseline concentrations of these molecules were not significantly higher in the dogs with pyometra than in the healthy controls but decreased following the removal of the inflamed uterus, thus indicating their usefulness in the postoperative period in dogs with pyometra [9].

IL-6 and HMGB1 levels usually increase in canine endotoxaemia and systemic inflammation [5, 7]; however, changes in their levels were not statistically significant in our study. IL-6 is a major proinflammatory cytokine released during an early phase of endotoxaemia [17], whereas HMGB1 is a late mediator, released by damaged or killed cells [27]. Because the analysed pyometra cases did not develop severe sepsis or organ damage, the peak concentrations of these inflammatory parameters might not have been persistent, or no peak levels were reached. However, the concentrations did significantly drop after surgical correction, and thus, IL-6 and HMGB1 could be useful biomarkers for therapeutic monitoring.

Both human and animal studies have suggested that an increase in the PCT concentration may be associated with serious infections and endotoxaemia $[28,29]$ and demonstrated that PCT acted as an APP in dogs. In humans, PCT is used for monitoring during treatment and as a prognostic marker [30]. Although PCT did not discriminate subjects with pyometra from healthy dogs, its concentration was significantly lower after surgical correction. Moreover, there were significant correlations between PCT levels and several types of clinical data, such as haematocrit, monocyte counts, BUN, total calcium, albumin, globulin, and ALP concentrations. Thus, application of PCT in clinical practice as a relevant surrogate biomarker for organ dysfunction and the severity of disease may be suggested.

Our study has several potential limitations, one of which is that the identification and assessment of the severity of pyometra were subjective. Additionally, the diagnosis of pyometra was confirmed based on gross findings, making it difficult to distinguish sepsis and SIRS, as gross confirmation of infection may or may not correspond to systemic illness [31]. However, the high frequency of clinical signs, abnormalities in blood tests, and persistent suppurative purulence suggested a systemic inflammatory response as a possible explanation of abnormal clinical criteria. Finally, all subjects survived until discharge, and thus, we could not compare parameters between the survival and non-survival groups. Further studies are necessary to validate the prognostic indicators.

\section{Conclusion}

cfDNA, CRP, and SAA have the potential to be used as clinically appropriate biomarkers for screening systemic inflammation in canine pyometra, whereas PCT, IL-6, and HMGB1 may be useful biomarkers for the therapeutic monitoring.

\section{Methods}

\subsection{Study design, ethical approval, and sampling}

A prospective randomised in vitro analysis of several biomarkers of inflammation was based on continuous monitoring of blood samples before and after surgical OHE. The study was conducted with the approval of the Institutional Animal Care and Use Committee of Gyeongsang National University (approval number: IACUC GNU-190218-D0010).

Dogs with pyometra diagnosed during 2018-2019 were included in this study. In total, 116 female dogs of various breeds, weights, and ages were included, of which 90 cases had pyometra, and 26 cases were healthy controls. Confirmation of the diagnosis of pyometra was based on previously proposed definitions [32,33]. The medical records of the dogs with pyometra, including the history, signalment, physical examination, clinical signs, and routine blood tests, were analysed. Healthy, client-owned female dogs served as controls for comparison. Prior to surgery, dogs were classified as healthy based on unremarkable findings in the history, physical examinations, and blood tests. Following surgery, consecutive samples from 22 dogs with pyometra and nine healthy controls were compared. 
Initial blood samples were collected at the time of presentation (pre-OHE), and then consecutive blood samples were collected within 3 days following surgical treatment (post-OHE). Samples were collected via venipuncture and stored in EDTA and lithium heparin tubes. The EDTA blood samples were analysed using an automatic haematology analyser. Heparinised plasma was stored at $-80^{\circ} \mathrm{C}$ for analysis of inflammatory biomarkers.

\subsection{Clinical and laboratory analyses}

To assess organ injury and the overall clinical status of the dogs, acid-base balance, electrolyte concentrations, and serum biochemical parameters were analysed using a blood gas analyser (pHOx; Nova Biomedical, Waltham, MA, USA) and a Catalyst Dx chemistry analyser (IDEXX, Westbrook, ME, USA).

The measurement of cell-free DNA (cfDNA), previously validated for use in dogs [25], was performed using a benchtop fluorimeter (Qubit 1.0; Life Sciences, Carlsbad, CA, USA) and the Qubit dsDNA HS assay kit, according to the manufacturer's instructions.

Canine C-reactive protein (CRP), serum amyloid A (SAA) (Phase CRP and SAA kits; Tridelta Development, Ltd., Maynooth, Ireland) [34, 35], IL-6 (DuoSet ELISA development kit; R\&D Systems, Minneapolis, MN, USA) [7, 17, 36], procalcitonin (PCT) (Biovendor LLC, Asheville, NC, USA) [28], and high-mobility group box 1 (HMGB1) (MyBiosource, San Diego, CA, USA) [7] were measured using commercial ELISA kits according to the manufacturers' instructions. The lower limits of detection were $7.5 \mathrm{ng} / \mathrm{mL}, 10 \mathrm{ng} / \mathrm{mL}, 62.5 \mathrm{pg} / \mathrm{mL}, 12.5 \mathrm{pg} / \mathrm{mL}$, and $6.25 \mathrm{ng} / \mathrm{mL}$, respectively. All biomarker measurements were performed in duplicate with appropriate controls.

\subsection{Statistical analysis}

All results are expressed as the mean \pm SD. The significance of differences between the subjects with pyometra and healthy animals was calculated using the Mann-Whitney U-test. Linear correlation between two variables was tested using Pearson's correlation coefficient. For continuous variables, the Wilcoxon two-sample test was used to evaluate differences between the dogs with pyometra and healthy ones and between pre- and post-OHE subjects. Statistical significance was set at $P<0.05$. The SPSS 25.0 software package (SPSS, Inc, Chicago, IL, USA) was used to perform all statistical analyses. All graphs were plotted using GraphPad Prism 8.0 (GraphPad Software, La Jolla, CA, USA).

\section{Abbreviations}

ALP, alkaline phosphatase; ALT, alanine aminotransferase; APP, acute-phase protein; BUN, blood urea nitrogen; cfDNA, cellfree DNA; CRP, C-reactive protein; HMGB1, high-mobility group box 1; NET, neutrophil extracellular trap; OHE, ovariohysterectomy; PCT, procalcitonin; ROC, receiver operating characteristic; SAA, serum amyloid A; SIRS, systemic inflammatory response syndrome; WBC, white blood cell.

\section{Declarations}

Not applicable

\section{Ethics approval and consent to participate}

The study was conducted with the approval of the Institutional Animal Care and Use Committee of Gyeongsang National University (approval number: IACUC GNU-190218-D0010), and written informed consents were obtained from all dog owners prior to sample collection.

\section{Consent for publication}

Not applicable.

\section{Availability of data and materials}


Not applicable.

\section{Competing Interests}

The authors declare no conflict of interest.

\section{Funding}

This work was carried out with the support of the Cooperative Research Program for Agriculture Science \& Technology Development (Project No. PJ01284305) Rural Development Administration, Republic of Korea. This research was supported by Basic Science Research Program through the National Research Foundation of Korea (NRF) funded by the Ministry of Science, ICT \& Future Planning (2020R1C1C1008675). Funding sources had no involvement in study design, research conduct, or manuscript preparation.

\section{Authors' contributions}

SA, JP, SK, DJ and DY designed all experiments. SA, HH, SK collected data, and SA, JP and DY analysed data. SA and DY drafted the manuscript. All authors approved of the final manuscript for publication.

\section{Acknowledgements}

Not applicable.

\section{References}

1. Conti-Patara A, de Araújo Caldeira J, de Mattos-Junior E, de Carvalho HdS, Reinoldes A, Pedron BG, Patara M, Francisco Talib MS, Faustino M, de Oliveira CM, et al. Changes in tissue perfusion parameters in dogs with severe sepsis/septic shock in response to goal-directed hemodynamic optimization at admission to ICU and the relation to outcome. Journal of Veterinary Emergency Critical Care. 2012;22(4):409-18.

2. Eckersall PD, Bell R. Acute phase proteins: Biomarkers of infection and inflammation in veterinary medicine. Vet $\mathrm{J}$. 2010;185(1):23-7.

3. Fransson BA, Lagerstedt A-S, Bergstrom A, Hagman R, Park JS, Chew BP, Evans MA, Ragle CA. C-reactive protein, tumor necrosis factor $a$, and interleukin- 6 in dogs with pyometra and SIRS. Journal of Veterinary Emergency Critical Care. 2007;17(4):373-81.

4. Karlsson I, Hagman R, Johannisson A, Wang L, Karlstam E, Wernersson S. Cytokines as Immunological Markers for Systemic Inflammation in Dogs with Pyometra. Reprod Domest Anim. 2012;47(s6):337-41.

5. Rau S. Kohn, Barbara, Richter, Constance, Fenske, Nora, Küchenhoff, Helmut, Hartmann, Katrin, Härtle, Stefan, Kaspers, Bernd, Hirschberger J: Plasma interleukin- 6 response is predictive for severity and mortality in canine systemic inflammatory response syndrome and sepsis. Vet Clin Pathol. 2007;36(3):253-60.

6. Troia R, Giunti M, Calipa S, Goggs R. Cell-Free DNA, high-mobility group box-1, and procalcitonin concentrations in dogs with gastric dilatation-volvulus syndrome. Frontiers in veterinary science. 2018;5:67.

7. Yu DH, Nho DH, Song RH, Kim SH, Lee MJ, Nemzek JA, Park J. High-mobility group box 1 as a surrogate prognostic marker in dogs with systemic inflammatory response syndrome. Journal of Veterinary Emergency Critical Care. 2010;20(3):298-302.

8. Hagman R, Kindahl H, Fransson B, Bergström A, Holst BS, Lagerstedt A-S. Differentiation between pyometra and cystic endometrial hyperplasia/mucometra in bitches by prostaglandin F2a metabolite analysis. Theriogenology. 2006;66(2):198-206. 
9. Dąbrowski R, Pastor J, Szczubiał M, Piech T, Bochniarz M, Wawron W, Tvarijonaviciute A. Serum IL-6 and IL-10 concentrations in bitches with pyometra undergoing ovariohysterectomy. Acta Vet Scand. 2015;57(1):61.

10. Karlsson I, Hagman R, Johannisson A, Wang L, Sodersten F, Wernersson S. Multiplex cytokine analyses in dogs with pyometra suggest involvement of KC-like chemokine in canine bacterial sepsis. Vet Immunol Immunopathol. 2016;170:41-6.

11. Jitpean S, Holst BS, Hoglund OV, Pettersson A, Olsson U, Strage E, Sodersten F, Hagman R. Serum insulin-like growth factor-I, iron, C-reactive protein, and serum amyloid A for prediction of outcome in dogs with pyometra. Theriogenology. 2014;82(1):43-8.

12. Karlsson I, Wernersson S, Ambrosen A, Kindahl H, Sodersten F, Wang L, Hagman R. Increased concentrations of Creactive protein but not high-mobility group box 1 in dogs with naturally occurring sepsis. Vet Immunol Immunopathol. 2013;156(1-2):64-72.

13. Chikazawa S, Dunning MD. A review of anaemia of inflammatory disease in dogs and cats. J Small Anim Pract. 2016;57(7):348-53.

14. Fransson B, Lagerstedt AS, Hellmen E, Jonsson P. Bacteriological findings, blood chemistry profile and plasma endotoxin levels in bitches with pyometra or other uterine diseases. Zentralbl Veterinarmed A. 1997;44(7):417-26.

15. Deschepper J, Vanderstock J, Capiau E. Anaemia and leucocytosis in one hundred and twelve dogs with pyometra. J Small Anim Pract. 1987;28(2):137-45.

16. Verstegen J, Dhaliwal G, Verstegen-Onclin K. Mucometra, cystic endometrial hyperplasia, and pyometra in the bitch: advances in treatment and assessment of future reproductive success. Theriogenology. 2008;70(3):364-74.

17. Yu DH, Kim B, Park J. Pathophysiologic and immunologic changes in a canine endotoxemia over a period of 24 hours. J Vet Med Sci. 2012;74(5):537-44.

18. Yilmaz Z, Ilcol YO, Ulus IH. Endotoxin increases plasma leptin and ghrelin levels in dogs. Crit Care Med. 2008;36(3):828-33.

19. Dabrowski R, Wawron W, Kostro K. Changes in CRP, SAA and haptoglobin produced in response to ovariohysterectomy in healthy bitches and those with pyometra. Theriogenology. 2007;67(2):321-7.

20. Enginler S, Ateş A, Diren Sığırcı B, Sontaş B, Sönmez K, Karaçam E, Ekici H, Evkuran Dal G, Gürel A. Measurement of Creactive protein and Prostaglandin F2a Metabolite Concentrations in Differentiation of Canine Pyometra and Cystic Endometrial Hyperplasia/Mucometra. Reprod Domest Anim. 2014;49(4):641-7.

21. Jitpean S, Pettersson A, Höglund OV, Holst BS, Olsson U, Hagman R. Increased concentrations of Serum amyloid A in dogs with sepsis caused by pyometra. BMC Veterinary Research. 2014;10(1):273.

22. Letendre JA, Goggs R. Determining prognosis in canine sepsis by bedside measurement of cell-free DNA and nucleosomes. Journal of Veterinary Emergency Critical Care. 2018;28(6):503-11.

23. Macher H, Egea-Guerrero JJ, Revuelto-Rey J, Gordillo-Escobar E, Enamorado-Enamorado J, Boza A, Rodriguez A, Molinero P, Guerrero JM, Dominguez-Roldan JM, et al. Role of early cell-free DNA levels decrease as a predictive marker of fatal outcome after severe traumatic brain injury. Clin Chim Acta. 2012;414:12-7.

24. Christensen MB, Langhorn R, Goddard A, Andreasen EB, Moldal E, Tvarijonaviciute A, Kirpensteijn J, Jakobsen S, Persson F, Kjelgaard-Hansen M. Comparison of serum amyloid A and C-reactive protein as diagnostic markers of systemic inflammation in dogs. The Canadian veterinary journal = La revue veterinaire canadienne. 2014;55(2):161-8.

25. Burnett DL, Cave NJ, Gedye KR, Bridges JP. Investigation of cell-free DNA in canine plasma and its relation to disease. Veterinary Quarterly. 2016;36(3):122-9.

26. Ishida A, Ohno K, Fukushima K, Nakashima K, Takahashi M, Goto-Koshino Y, Fujino Y, Tsujimoto H. Plasma highmobility group box 1 (HMGB1) in dogs with various diseases: comparison with C-reactive protein. J Vet Med Sci. 2011;73(9):1127-32. 
27. Wang H, Bloom O, Zhang M, Vishnubhakat JM, Ombrellino M, Che J, Frazier A, Yang H, Ivanova S, Borovikova L. HMG-1 as a late mediator of endotoxin lethality in mice. Science. 1999;285(5425):248-51.

28. Goggs R, Milloway M, Troia R, Giunti M. Plasma procalcitonin concentrations are increased in dogs with sepsis. Veterinary record open. 2018;5(1):e000255.

29. Kuzi S, Aroch I, Peleg K, Karnieli O, Klement E, Dank G. Canine procalcitonin messenger RNA expression. Journal of veterinary diagnostic investigation. 2008;20(5):629-33.

30. Castelli G, Pognani C, Cita M, Stuani A, Sgarbi L, Paladini R. Procalcitonin, C-reactive protein, white blood cells and SOFA score in ICU: diagnosis and monitoring of sepsis. Minerva Anestesiol. 2006;72(1/2):69.

31. Hauptman JG, Walshaw R, Olivier NB. Evaluation of the Sensitivity and Specificity of Diagnostic Criteria for Sepsis in Dogs. Vet Surg. 1997;26(5):393-7.

32. Borresen B. Pyometra in the dog - a pathophysiological investigation. I. The pyometra syndrome, a review. Nordisk Veterinaermedicin. 1975;27(10):508-17.

33. Hagman R. Diagnostic and prognostic markers for uterine diseases in dogs. Reprod Domest Anim. 2014;49:16-20.

34. Kjelgaard-Hansen M, Kristensen AT, Jensen AL. Evaluation of a commercially available enzyme-linked immunosorbent assay (ELISA) for the determination of C-reactive protein in canine serum. J Vet Med Ser A. 2003;50(3):164-8.

35. McDonald TL, Weber A, Smith JW. A monoclonal antibody sandwich immunoassay for serum amyloid A (SAA) protein. J Immunol Methods. 1991;144(2):149-55.

36. Song R, Kim J, Yu D, Park C, Park J. Kinetics of IL-6 and TNF-alpha changes in a canine model of sepsis induced by endotoxin. Vet Immunol Immunopathol. 2012;146(2):143-9.

\section{Tables}

\section{Table 1}

Mean variables for clinical data from pyometra and healthy female dogs. 


\begin{tabular}{|c|c|c|c|}
\hline Variables & Pyometra $(n=90)$ & Healthy $(n=26)$ & $P$-value \\
\hline $\operatorname{RBC}\left(\times 10^{12} / \mathrm{L}\right)$ & $6.10 \pm 0.12$ & $7.01 \pm 0.18$ & 0.001 \\
\hline HCT & $0.39 \pm 0.01$ & $0.47 \pm 0.01$ & 0.000 \\
\hline HGB (g/L) & $140.60 \pm 5.20$ & $161.80 \pm 4.60$ & 0.000 \\
\hline WBC $\left(\times 10^{9} / \mathrm{L}\right)$ & $24.29 \pm 2.08$ & $10.33 \pm 0.55$ & 0.001 \\
\hline $\operatorname{NEU}\left(\times 10^{9} / \mathrm{L}\right)$ & $16.91 \pm 1.67$ & $6.91 \pm 0.44$ & 0.001 \\
\hline LYM $\left(\times 10^{9} / \mathrm{L}\right)$ & $3.96 \pm 0.46$ & $2.49 \pm 0.31$ & 0.116 \\
\hline MONO $\left(\times 10^{9} / \mathrm{L}\right)$ & $1.95 \pm 0.29$ & $0.63 \pm 0.07$ & 0.005 \\
\hline $\operatorname{EOS}\left(\times 10^{9} / \mathrm{L}\right)$ & $0.43 \pm 0.08$ & $0.29 \pm 0.06$ & 0.470 \\
\hline BASO $\left(\times 10^{9} / \mathrm{L}\right)$ & $0.06 \pm 0.02$ & $0.04 \pm 0.01$ & 0.025 \\
\hline $\operatorname{PLT}\left(\times 10^{9} / \mathrm{L}\right)$ & $326.62 \pm 20.45$ & $348.42 \pm 34.97$ & 0.428 \\
\hline Glucose (mmol/L) & $6.60 \pm 0.33$ & $5.69 \pm 0.24$ & 0.185 \\
\hline BUN (mmol/L) & $8.51 \pm 0.97$ & $6.71 \pm 0.43$ & 0.191 \\
\hline Creatinine $(\mu \mathrm{mol} / \mathrm{L})$ & $101.66 \pm 16.80$ & $68.95 \pm 5.30$ & 0.160 \\
\hline Phosphorus (mmol/L) & $1.86 \pm 0.14$ & $1.51 \pm 0.09$ & 0.346 \\
\hline Total Ca (mmol/L) & $2.38 \pm 0.04$ & $2.30 \pm 0.10$ & 0.895 \\
\hline Total protein $(\mathrm{g} / \mathrm{L})$ & $80.70 \pm 8.20$ & $63.40 \pm 1.50$ & 0.000 \\
\hline Albumin (g/L) & $26.60 \pm 0.50$ & $30.60 \pm 0.90$ & 0.001 \\
\hline Globulin (g/L) & $46.60 \pm 1.30$ & $32.90 \pm 1.10$ & 0.000 \\
\hline $\operatorname{ALT}(U / L)$ & $83.29 \pm 16.48$ & $74.85 \pm 8.13$ & 0.011 \\
\hline $\operatorname{ALP}(U / L)$ & $497.85 \pm 81.59$ & $126.00 \pm 18.61$ & 0.000 \\
\hline GGT (U/L) & $13.00 \pm 4.99$ & $5.63 \pm 0.87$ & 0.727 \\
\hline Total bilirubin $(\mu \mathrm{mol} / \mathrm{L})$ & $5.64 \pm 0.86$ & $4.79 \pm 1.03$ & 0.550 \\
\hline Cholesterol $(\mu \mathrm{mol} / \mathrm{L})$ & $6.55 \pm 0.31$ & $4.97 \pm 0.39$ & 0.010 \\
\hline Amylase (U/L) & $1334.57 \pm 354.85$ & $561.35 \pm 48.85$ & 0.008 \\
\hline Lipase (U/L) & $651.54 \pm 159.95$ & $783.83 \pm 79.26$ & 0.000 \\
\hline $\mathrm{pH}$ & $7.39 \pm 0.01$ & $7.40 \pm 0.01$ & 0.446 \\
\hline $\mathrm{Na}(\mathrm{mmol} / \mathrm{L})$ & $145.45 \pm 1.07$ & $146.28 \pm 0.76$ & 0.808 \\
\hline $\mathrm{K}(\mathrm{mmol} / \mathrm{L})$ & $4.25 \pm 0.07$ & $4.46 \pm 0.13$ & 0.185 \\
\hline $\mathrm{Cl}(\mathrm{mmol} / \mathrm{L})$ & $107.07 \pm 1.968$ & $114.36 \pm 0.69$ & 0.002 \\
\hline $\mathrm{iCa}(\mathrm{mmol} / \mathrm{L})$ & $1.36 \pm 0.08$ & $1.25 \pm 0.02$ & 0.644 \\
\hline $\mathrm{iMg}(\mathrm{mmol} / \mathrm{L})$ & $0.51 \pm 0.01$ & $0.46 \pm 0.01$ & 0.124 \\
\hline $\mathrm{HCO} 3(\mathrm{mmol} / \mathrm{L})$ & $20.18 \pm 1.04$ & $19.51 \pm 0.55$ & 0.669 \\
\hline
\end{tabular}




$\begin{array}{|llll|}\text { Lactate }(\mathrm{mmol} / \mathrm{L}) & 2.16 \pm 0.28 & 2.11 \pm 0.31 & 0.869\end{array}$

All data are presented as mean \pm SD. The $P$ values represented the comparison the clinical data between the pyometra and healthy dogs.

RBC, red blood cells; HGB, haemoglobin; HCT, haematocrit; WBC, white blood cells; NEU, neutrophils; LYM, lymphocytes; MONO, monocytes; EOS, eosinophils; BASO, basophils; PLT, platelet; BUN, blood urea nitrogen; ALT, alanine aminotransferase; ALP, alkaline phosphatase; GGT, gamma-glutamyl transpeptidase; iCa, ionised calcium; iMg, ionised magnesium; $\mathrm{HCO}$, bicarbonate.

Table 2. Evaluation of Pearson's rank correlation coefficients between parameters in dogs with pyometra. 


\begin{tabular}{|c|c|c|c|c|c|c|c|c|c|c|c|c|}
\hline \multirow[t]{2}{*}{ Variables } & \multicolumn{2}{|c|}{$\begin{array}{l}\text { cfDNA } \\
(\mu g / L)\end{array}$} & \multicolumn{2}{|c|}{$\begin{array}{l}\text { CRP } \\
(\mathrm{mg} / \mathrm{L})\end{array}$} & \multicolumn{2}{|c|}{$\begin{array}{l}\text { SAA } \\
(\mathrm{mg} / \mathrm{L})\end{array}$} & \multicolumn{2}{|c|}{$\begin{array}{l}\text { IL-6 } \\
(\mathrm{ng} / \mathrm{ml})\end{array}$} & \multicolumn{2}{|c|}{$\begin{array}{l}\text { РCT } \\
(\mathrm{pg} / \mathrm{ml})\end{array}$} & \multicolumn{2}{|c|}{$\begin{array}{l}\text { HMGB1 } \\
\text { (ng/ml) }\end{array}$} \\
\hline & $r$ & $P$ value & $r$ & $\begin{array}{l}P \\
\text { value }\end{array}$ & $\mathrm{r}$ & $\begin{array}{l}P \text { - } \\
\text { value }\end{array}$ & $r$ & $\begin{array}{l}P \\
\text { value }\end{array}$ & $r$ & $\begin{array}{l}P \\
\text { value }\end{array}$ & $r$ & $\begin{array}{l}P \\
\text { value }\end{array}$ \\
\hline $\begin{array}{l}\text { RBC } \\
\left(\times 10^{12} / \mathrm{L}\right)\end{array}$ & -0.02 & 0.912 & -0.08 & 0.622 & -0.02 & 0.902 & 0.01 & 0.912 & -0.04 & 0.771 & 0.12 & 0.463 \\
\hline НСT & 0.00 & 0.994 & 0.14 & 0.411 & 0.10 & 0.533 & 0.06 & 0.693 & -0.33 & 0.043 & 0.30 & 0.086 \\
\hline $\mathrm{HGB}(\mathrm{g} / \mathrm{L})$ & -0.12 & 0.473 & -0.20 & 0.224 & -0.12 & 0.458 & -0.02 & 0.901 & 0.18 & 0.282 & -0.10 & 0.564 \\
\hline $\begin{array}{l}\text { WBC } \\
\left(\times 10^{9} / L\right)\end{array}$ & 0.46 & 0.000 & 0.22 & 0.195 & -0.03 & 0.821 & 0.03 & 0.828 & 0.23 & 0.178 & -0.07 & 0.693 \\
\hline $\begin{array}{l}\text { NEU } \\
\left(\times 10^{9} / \mathrm{L}\right)\end{array}$ & 0.47 & 0.000 & 0.24 & 0.153 & -0.01 & 0.943 & 0.04 & 0.804 & 0.19 & 0.263 & -0.05 & 0.742 \\
\hline $\begin{array}{l}\text { LYM } \\
\text { (×109/L) }\end{array}$ & 0.11 & 0.492 & 0.01 & 0.937 & -0.12 & 0.464 & 0.01 & 0.948 & 0.09 & 0.587 & -0.05 & 0.776 \\
\hline $\begin{array}{l}\text { MONO } \\
\left(\times 10^{9} / L\right)\end{array}$ & 0.28 & 0.091 & 0.09 & 0.598 & -0.13 & 0.452 & 0.00 & 0.992 & 0.38 & 0.025 & -0.09 & 0.613 \\
\hline $\begin{array}{l}\text { EOS } \\
\left(\times 10^{9} / L\right)\end{array}$ & 0.20 & 0.223 & 0.23 & 0.187 & 0.19 & 0.268 & 0.05 & 0.776 & -0.13 & 0.436 & -0.13 & 0.455 \\
\hline $\begin{array}{l}\text { BASO } \\
\left(\times 10^{9} / \mathrm{L}\right)\end{array}$ & 0.42 & 0.014 & 0.16 & 0.346 & 0.09 & 0.585 & -0.06 & 0.724 & 0.29 & 0.088 & -0.03 & 0.853 \\
\hline $\begin{array}{l}\text { PLT } \\
\left(\times 10^{9} / \mathrm{L}\right)\end{array}$ & -0.30 & 0.072 & -0.21 & 0.215 & -0.09 & 0.608 & -0.32 & 0.057 & 0.10 & 0.534 & -0.19 & 0.271 \\
\hline $\begin{array}{l}\text { Glucose } \\
\text { (mmol/L) }\end{array}$ & -0.09 & 0.583 & -0.26 & 0.133 & -0.15 & 0.379 & -0.03 & 0.864 & -0.12 & 0.477 & -0.20 & 0.278 \\
\hline $\begin{array}{l}\text { BUN } \\
(\mathrm{mmol} / \mathrm{L})\end{array}$ & 0.28 & 0.095 & 0.14 & 0.418 & 0.09 & 0.564 & -0.13 & 0.447 & 0.41 & 0.012 & -0.16 & 0.365 \\
\hline $\begin{array}{l}\text { Creatinine } \\
(\mu \mathrm{mol} / \mathrm{L})\end{array}$ & 0.17 & 0.302 & -0.22 & 0.189 & -0.11 & 0.513 & -0.07 & 0.653 & 0.12 & 0.455 & -0.26 & 0.134 \\
\hline $\begin{array}{l}\text { Phosphorus } \\
\text { (mmol/L) }\end{array}$ & 0.24 & 0.191 & 0.08 & 0.655 & 0.05 & 0.758 & 0.11 & 0.527 & 0.28 & 0.123 & -0.11 & 0.559 \\
\hline $\begin{array}{l}\text { Total Ca } \\
(\mathrm{mmol} / \mathrm{L})\end{array}$ & 0.03 & 0.862 & -0.15 & 0.383 & -0.04 & 0.805 & 0.01 & 0.915 & 0.44 & 0.001 & 0.03 & 0.866 \\
\hline $\begin{array}{l}\text { Total protein } \\
\text { (g/L) }\end{array}$ & -0.07 & 0.663 & 0.17 & 0.314 & -0.00 & 0.996 & 0.88 & 0.001 & -0.07 & 0.642 & 0.18 & 0.308 \\
\hline $\begin{array}{l}\text { Albumin } \\
(\mathrm{g} / \mathrm{L})\end{array}$ & -0.42 & 0.012 & -0.11 & 0.496 & 0.15 & 0.353 & -0.35 & 0.843 & -0.37 & 0.025 & 0.15 & 0.394 \\
\hline $\begin{array}{l}\text { Globulin } \\
(\mathrm{g} / \mathrm{L})\end{array}$ & 0.44 & 0.002 & 0.31 & 0.068 & 0.11 & 0.518 & 0.29 & 0.086 & 0.33 & 0.043 & 0.09 & 0.607 \\
\hline ALT (U/L) & -0.15 & 0.363 & -0.30 & 0.079 & -0.16 & 0.345 & -0.06 & 0.702 & 0.10 & 0.535 & 0.07 & 0.664 \\
\hline $\operatorname{ALP}(\mathrm{U} / \mathrm{L})$ & -0.03 & 0.824 & -0.23 & 0.160 & -0.05 & 0.755 & -0.09 & 0.575 & 0.34 & 0.036 & 0.14 & 0.427 \\
\hline GGT (U/L) & 0.01 & 0.951 & -0.37 & 0.152 & -0.18 & 0.483 & -0.15 & 0.562 & 0.05 & 0.841 & -0.15 & 0.572 \\
\hline Total & 0.05 & 0.744 & 0.05 & 0.776 & 0.06 & 0.717 & -0.04 & 0.795 & 0.12 & 0.466 & -0.11 & 0.543 \\
\hline
\end{tabular}




\begin{tabular}{|c|c|c|c|c|c|c|c|c|c|c|c|c|}
\hline $\begin{array}{l}\text { Cholesterol } \\
(\mu \mathrm{mol} / \mathrm{L})\end{array}$ & 0.26 & 0.153 & 0.32 & 0.073 & 0.67 & 0.000 & -0.01 & 0.954 & -0.16 & 0.384 & 0.12 & 0.516 \\
\hline $\begin{array}{l}\text { Amylase } \\
(\mathrm{U} / \mathrm{L})\end{array}$ & 0.16 & 0.357 & 0.05 & 0.774 & -0.03 & 0.874 & -0.06 & 0.743 & -0.13 & 0.463 & 0.35 & 0.052 \\
\hline Lipase (U/L) & -0.04 & 0.792 & -0.26 & 0.152 & -0.14 & 0.445 & -0.12 & 0.495 & -0.06 & 0.726 & -0.00 & 0.998 \\
\hline $\mathrm{pH}$ & 0.38 & 0.033 & -0.17 & 0.356 & -0.24 & 0.193 & 0.12 & 0.524 & 0.08 & 0.649 & -0.03 & 0.842 \\
\hline $\begin{array}{l}\mathrm{Na} \\
(\mathrm{mmol} / \mathrm{L})\end{array}$ & -0.40 & 0.026 & -0.20 & 0.267 & -0.24 & 0.187 & 0.04 & 0.823 & 0.23 & 0.192 & 0.20 & 0.286 \\
\hline $\mathrm{K}(\mathrm{mmol} / \mathrm{L})$ & -0.01 & 0.946 & -0.30 & 0.094 & -0.27 & 0.145 & 0.04 & 0.815 & 0.04 & 0.796 & 0.10 & 0.584 \\
\hline $\mathrm{Cl}(\mathrm{mmol} / \mathrm{L})$ & -0.40 & 0.029 & -0.27 & 0.143 & -0.02 & 0.876 & -0.01 & 0.947 & 0.119 & 0.294 & 0.17 & 0.363 \\
\hline $\begin{array}{l}\text { iCa } \\
\text { (mmol/L) }\end{array}$ & -0.13 & 0.487 & 0.16 & 0.386 & -0.12 & 0.523 & 0.43 & 0.014 & -0.04 & 0.818 & -0.13 & 0.497 \\
\hline $\begin{array}{l}\mathrm{iMg} \\
(\mathrm{mmol} / \mathrm{L})\end{array}$ & 0.25 & 0.263 & 0.51 & 0.011 & 0.50 & 0.012 & 0.12 & 0.582 & -0.16 & 0.475 & -0.11 & 0.592 \\
\hline $\begin{array}{l}\mathrm{HCO} 3 \\
(\mathrm{mmol} / \mathrm{L})\end{array}$ & 0.12 & 0.524 & -0.13 & 0.495 & -0.22 & 0.233 & -0.02 & 0.919 & -0.20 & 0.283 & -0.04 & 0.825 \\
\hline $\begin{array}{l}\text { Lactate } \\
(\mathrm{mmol} / \mathrm{L})\end{array}$ & -0.50 & 0.207 & -0.41 & 0.302 & -0.05 & 0.894 & -0.11 & 0.795 & 0.26 & 0.522 & -0.14 & 0.723 \\
\hline
\end{tabular}

cfDNA, cell-free DNA; CRP, C-reactive protein; SAA, serum amyloid A; IL-6, interleukin-6; PCT, procalcitonin; HMGB1, highmobility group box 1; RBC, red blood cells; HGB, haemoglobin; HCT, haematocrit; WBC, white blood cells; NEU, neutrophils; LYM, lymphocytes; MONO, monocytes; EOS, eosinophils; BASO, basophils; PLT, platelet; BUN, blood urea nitrogen; ALT, alanine aminotransferase; ALP, alkaline phosphatase; GGT, gamma-glutamyl transpeptidase; iCa, ionised calcium; iMg, ionised magnesium; $\mathrm{HCO}$, bicarbonate.

\section{Table 3}

Results of the Mann-Whitney U-test for differences in inflammatory parameters between the subgroups of pyometra (clinically worse dogs, higher or lower than reference intervals) differing in clinical data compared to healthy dogs. 


\begin{tabular}{|c|c|c|c|c|c|c|c|c|c|c|c|c|}
\hline \multirow[t]{2}{*}{ Subgroups } & \multicolumn{2}{|l|}{$\begin{array}{l}\text { cfDNA } \\
(\mu \mathrm{g} / \mathrm{L})\end{array}$} & \multicolumn{2}{|c|}{$\begin{array}{l}\text { CRP } \\
(\mathrm{mg} / \mathrm{L})\end{array}$} & \multicolumn{2}{|l|}{$\begin{array}{l}\text { SAA } \\
(\mathrm{mg} / \mathrm{L})\end{array}$} & \multicolumn{2}{|c|}{$\begin{array}{l}\text { IL-6 } \\
\text { (ng/ml) }\end{array}$} & \multicolumn{2}{|c|}{$\begin{array}{l}\text { РCT } \\
(\mathrm{pg} / \mathrm{ml})\end{array}$} & \multicolumn{2}{|c|}{$\begin{array}{l}\text { HMGB1 } \\
\text { (ng/ml) }\end{array}$} \\
\hline & Mean & $P$ & Mean & $P$ & Mean & $P$ & Mean & $P$ & Mean & $P$ & Mean & $P$ \\
\hline \multicolumn{13}{|l|}{ High } \\
\hline WBC & 18.71 & 0.002 & 19.67 & 0.000 & 19.43 & 0.000 & 15.95 & 0.596 & 14.86 & 0.541 & 11.45 & 0.315 \\
\hline NEU & 19.22 & 0.009 & 20.43 & 0.000 & 20.09 & 0.001 & 16.83 & 0.692 & 16.04 & 0.660 & 12.45 & 0.315 \\
\hline MONO & 17.67 & 0.001 & 18.28 & 0.000 & 17.72 & 0.001 & 14.50 & 0.566 & 13.72 & 0.797 & 10.56 & 0.421 \\
\hline BUN & 11.75 & 0.006 & 12.25 & 0.002 & 12.38 & 0.001 & 9.56 & 0.241 & 8.38 & 0.916 & 5.13 & 0.153 \\
\hline Creatinine & 10.00 & 0.028 & 11.00 & 0.003 & 9.60 & 0.057 & 8.20 & 0.317 & 6.80 & 0.884 & 3.60 & 0.439 \\
\hline Phosphate & 11.50 & 0.005 & 11.50 & 0.005 & 11.50 & 0.005 & 7.06 & 0.917 & 10.50 & 0.031 & 2.75 & 0.077 \\
\hline ALT & 12.44 & 0.003 & 12.22 & 0.005 & 11.22 & 0.054 & 9.22 & 0.811 & 8.89 & 0.923 & 5.67 & 0.166 \\
\hline ALP & 11.62 & 0.007 & 11.62 & 0.007 & 11.62 & 0.007 & 9.00 & 0.417 & 9.85 & 0.657 & 7.31 & 0.535 \\
\hline TP & 11.43 & 0.030 & 12.57 & 0.003 & 12.86 & 0.001 & 10.50 & 0.089 & 6.57 & 0.153 & 4.33 & 0.302 \\
\hline Globulin & 17.35 & 0.000 & 17.82 & 0.000 & 17.53 & 0.000 & 14.62 & 0.242 & 12.53 & 0.374 & 9.69 & 0.576 \\
\hline \multicolumn{13}{|l|}{ Low } \\
\hline HCT & 15.29 & 0.004 & 16.50 & 0.000 & 15.21 & 0.005 & 12.46 & 0.615 & 11.79 & 0.850 & 8.00 & 0.078 \\
\hline Albumin & 12.86 & 0.008 & 12.86 & 0.008 & 11.86 & 0.051 & 11.14 & 0.028 & 9.86 & 0.558 & 6.71 & 0.482 \\
\hline
\end{tabular}

cfDNA, cell-free DNA; CRP, C-reactive protein; SAA, serum amyloid A; IL-6, interleukin-6; PCT, procalcitonin; HMGB1, highmobility group box 1 ; WBC, white blood cells; NEU, neutrophils; MONO, monocytes; BUN, blood urea nitrogen; ALT, alanine aminotransferase; ALP, alkaline phosphatase; TP, total protein; HCT, haematocrit.

\section{Table 4}

Comparison of the pre- and post-OHE clinical data in dogs with pyometra $(n=22)$. 


\begin{tabular}{|c|c|c|c|}
\hline Variables & Pre-OHE & Post-OHE & $P$-value \\
\hline $\operatorname{RBC}\left(\times 10^{12} / \mathrm{L}\right)$ & $6.21 \pm 0.20$ & $5.05 \pm 0.19$ & 0.000 \\
\hline HCT & $0.41 \pm 0.01$ & $0.35 \pm 0.02$ & 0.000 \\
\hline $\mathrm{HGB}(\mathrm{g} / \mathrm{L})$ & $138.40 \pm 4.70$ & $114.60 \pm 5.10$ & 0.000 \\
\hline WBC $\left(\times 10^{9} / \mathrm{L}\right)$ & $30.68 \pm 5.13$ & $44.98 \pm 5.27$ & 0.003 \\
\hline $\operatorname{NEU}\left(\times 10^{9} / \mathrm{L}\right)$ & $24.65 \pm 4.19$ & $38.03 \pm 4.83$ & 0.002 \\
\hline LYM $\left(\times 10^{9} / \mathrm{L}\right)$ & $3.40 \pm 0.62$ & $4.31 \pm 0.94$ & 0.465 \\
\hline MONO $\left(\times 10^{9} / \mathrm{L}\right)$ & $1.68 \pm 0.31$ & $1.83 \pm 0.23$ & 0.434 \\
\hline $\operatorname{EOS}\left(\times 10^{9} / \mathrm{L}\right)$ & $0.48 \pm 0.17$ & $0.38 \pm 0.07$ & 0.676 \\
\hline BASO $\left(\times 10^{9} / \mathrm{L}\right)$ & $0.15 \pm 0.08$ & $0.20 \pm 0.08$ & 0.336 \\
\hline $\operatorname{PLT}\left(\times 10^{9} / \mathrm{L}\right)$ & $277.82 \pm 30.13$ & $293.64 \pm 27.25$ & 0.783 \\
\hline Glucose (mmol/L) & $6.16 \pm 0.41$ & $4.91 \pm 0.42$ & 0.037 \\
\hline BUN (mmol/L) & $6.76 \pm 1.76$ & $4.47 \pm 1.08$ & 0.023 \\
\hline Creatinine $(\mu \mathrm{mol} / \mathrm{L})$ & $143.21 \pm 61.88$ & $118.46 \pm 53.04$ & 0.019 \\
\hline Phosphorus (mmol/L) & $1.55 \pm 0.19$ & $1.47 \pm 0.11$ & 0.911 \\
\hline Total Ca (mmol/L) & $2.40 \pm 0.04$ & $2.20 \pm 0.04$ & 0.001 \\
\hline Total protein (g/L) & $106.9 \pm 32.10$ & $62.50 \pm 1.60$ & 0.000 \\
\hline Albumin (g/L) & $25.70 \pm 1.20$ & $22.50 \pm 0.60$ & 0.012 \\
\hline Globulin (g/L) & $49.50 \pm 2.50$ & $40.10 \pm 1.70$ & 0.000 \\
\hline ALT (U/L) & $52.14 \pm 11.17$ & $53.05 \pm 7.90$ & 0.390 \\
\hline $\operatorname{ALP}(U / L)$ & $463.82 \pm 136.16$ & $298.59 \pm 64.87$ & 0.012 \\
\hline GGT (U/L) & $22.00 \pm 12.10$ & $13.67 \pm 8.49$ & 0.105 \\
\hline Total bilirubin $(\mu \mathrm{mol} / \mathrm{L})$ & $3.25 \pm 0.34$ & $3.93 \pm 0.86$ & 0.392 \\
\hline Cholesterol $(\mu \mathrm{mol} / \mathrm{L})$ & $6.55 \pm 0.86$ & $5.13 \pm 0.70$ & 0.004 \\
\hline Amylase (U/L) & $2469.38 \pm 1109.78$ & $1147.52 \pm 188.78$ & 0.433 \\
\hline Lipase (U/L) & $256.59 \pm 90.34$ & $465.62 \pm 143.08$ & 0.322 \\
\hline $\mathrm{pH}$ & $7.40 \pm 0.01$ & $7.33 \pm 0.01$ & 0.003 \\
\hline $\mathrm{Na}(\mathrm{mmol} / \mathrm{L})$ & $147.48 \pm 1.51$ & $152.23 \pm 1.20$ & 0.003 \\
\hline $\mathrm{K}(\mathrm{mmol} / \mathrm{L})$ & $4.22 \pm 0.12$ & $3.76 \pm 0.12$ & 0.009 \\
\hline $\mathrm{Cl}(\mathrm{mmol} / \mathrm{L})$ & $108.12 \pm 1.95$ & $115.25 \pm 1.06$ & 0.000 \\
\hline iCa (mmol/L) & $1.46 \pm 0.17$ & $1.33 \pm 0.02$ & 0.025 \\
\hline $\mathrm{iMg}(\mathrm{mmol} / \mathrm{L})$ & $0.56 \pm 0.03$ & $0.54 \pm 0.02$ & 0.484 \\
\hline $\mathrm{HCO} 3$ (mmol/L) & $20.83 \pm 2.13$ & $19.57 \pm 1.03$ & 0.936 \\
\hline
\end{tabular}

Page 15/18 
All data are presented as mean \pm SD. The $P$ values represented the comparison the clinical data between the pre- and postOHE pyometra dogs.

RBC, red blood cells; HGB, haemoglobin; HCT, haematocrit; WBC, white blood cells; NEU, neutrophils; LYM, lymphocytes; MONO, monocytes; EOS, eosinophils; BASO, basophils; PLT, platelet; BUN, blood urea nitrogen; ALT, alanine aminotransferase; ALP, alkaline phosphatase; GGT, gamma-glutamyl transpeptidase; iCa, ionised calcium; iMg, ionised magnesium; $\mathrm{HCO}$, bicarbonate.

\section{Figures}

(A)
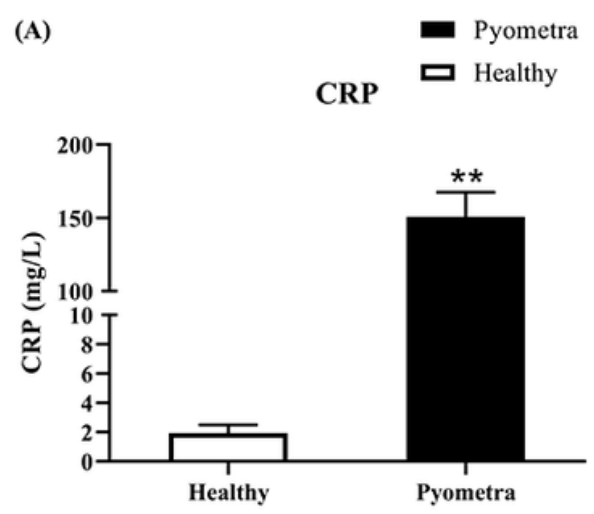

(D)
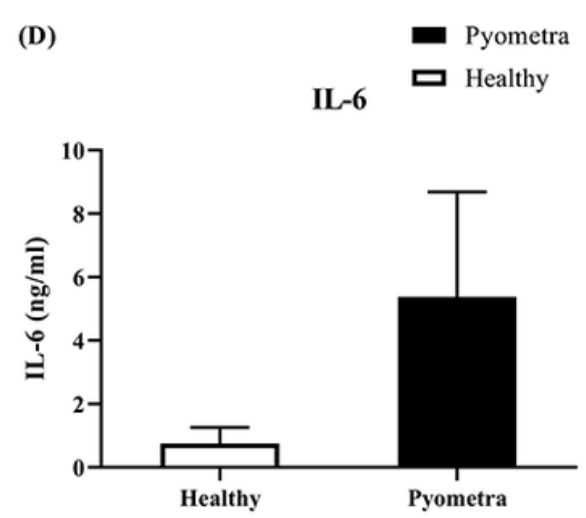

(B)

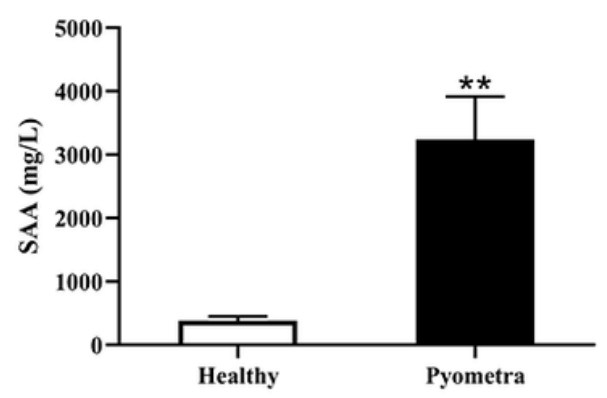

(E)
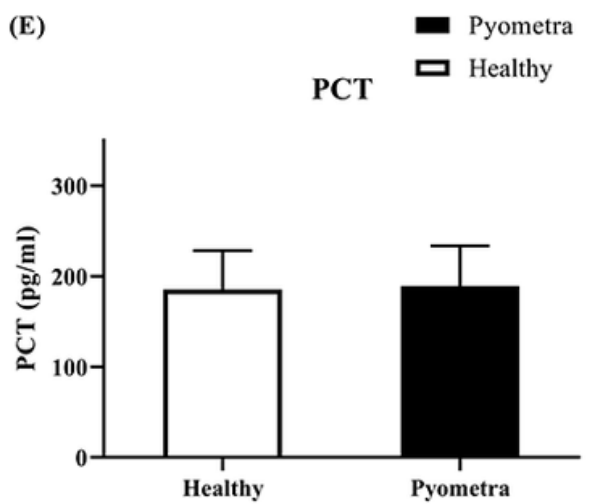

(C) Pyometra
cfDNA Healthy

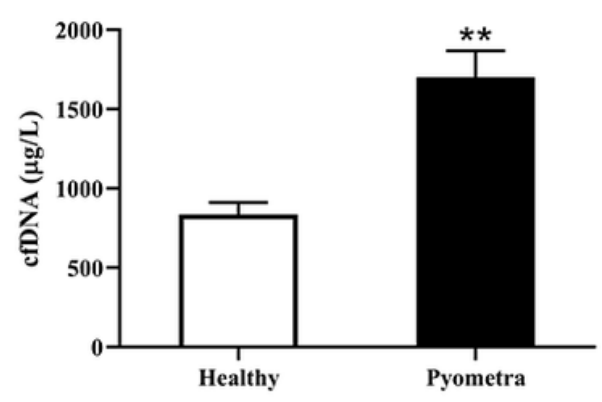

(F) HMGB1 ص Healthy

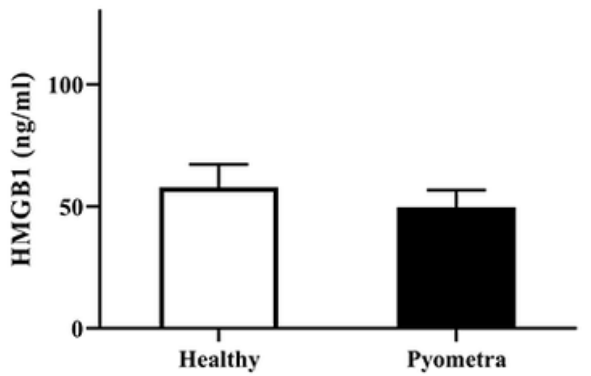

\section{Figure 1}

Plasma concentrations of inflammatory parameters in healthy controls and dogs with pyometra. (A) C-reactive protein (CRP); (B) serum amyloid A (SAA); (C) cell-free DNA (cfDNA); (D) IL-6; (E) procalcitonin (PCT); and (F) high-mobility group box 1 (HMGB1). All data are presented as the mean $\pm \mathrm{SD}$. ${ }^{\star *} \mathrm{P}<0.01 \mathrm{vs}$. healthy controls. 


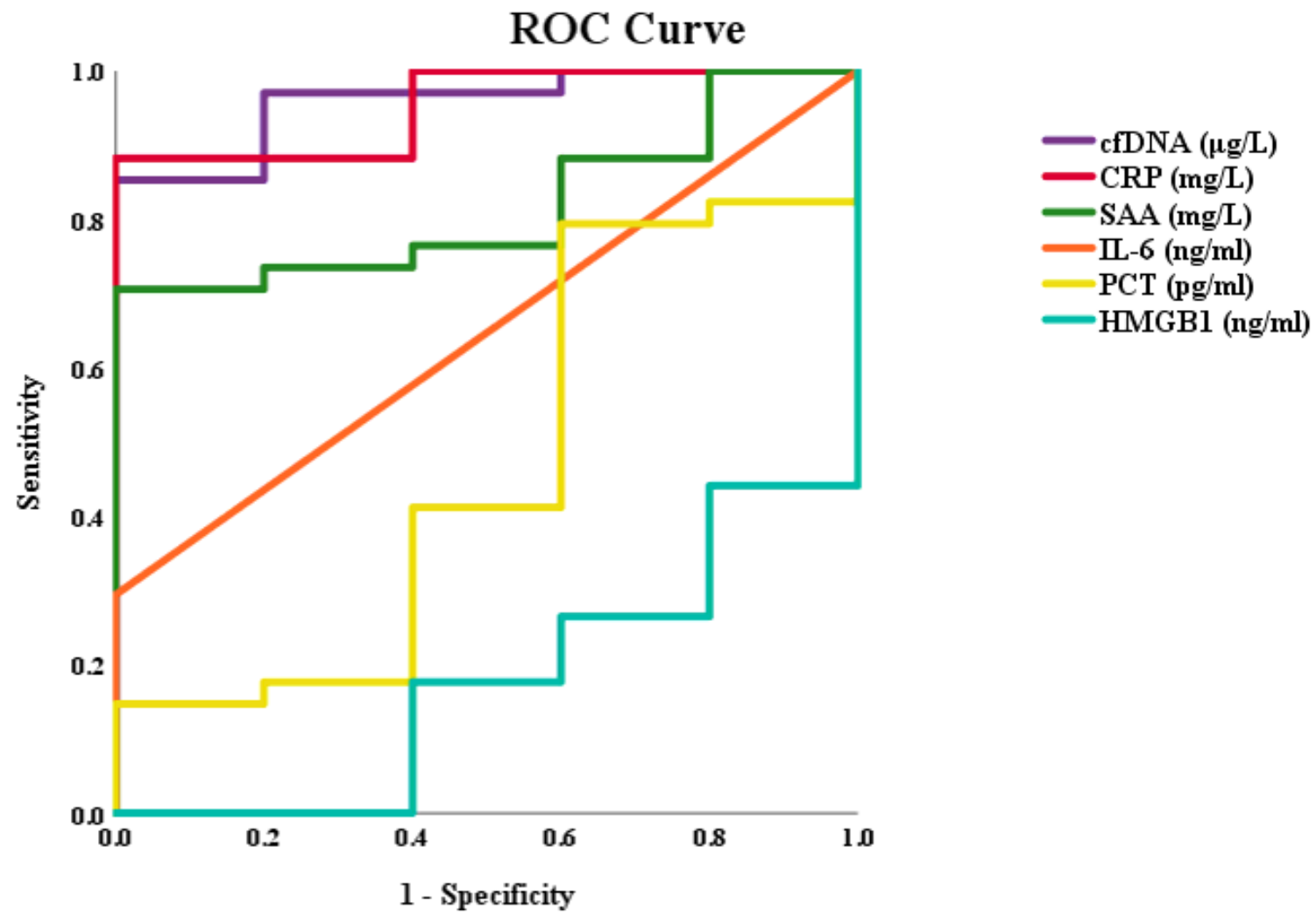

Figure 2

ROC curves comparing diagnostic sensitivity and specificity of each biomarker for canine pyometra. The $95 \%$ confidence intervals for the area under the curve (AUC) were 0.959 (0.893 to 1.0) for cell-free DNA (cfDNA) and 0.953 (0.882 to 1.0) for $C$-reactive protein $(C R P)$, which were both statistically significant $(P=0.001)$. The other AUC values were 0.818 for serum amyloid A (SAA), 0.647 for IL-6, 0.471 for procalcitonin (PCT), and 0.176 for high-mobility group box 1 (HMGB1), with no statistical significance. 
(A)

$$
\begin{aligned}
& \text { Pyometra } \\
& \text { CRP Healthy }
\end{aligned}
$$

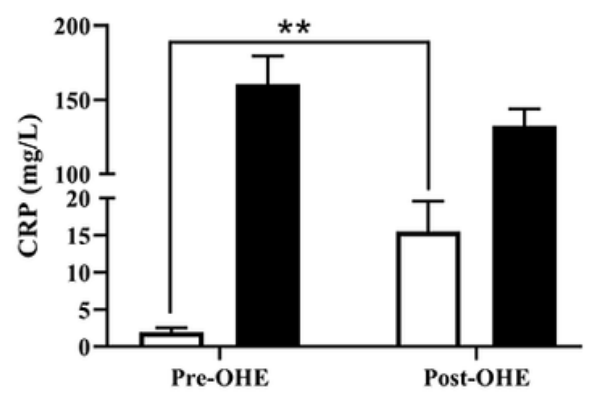

(D)
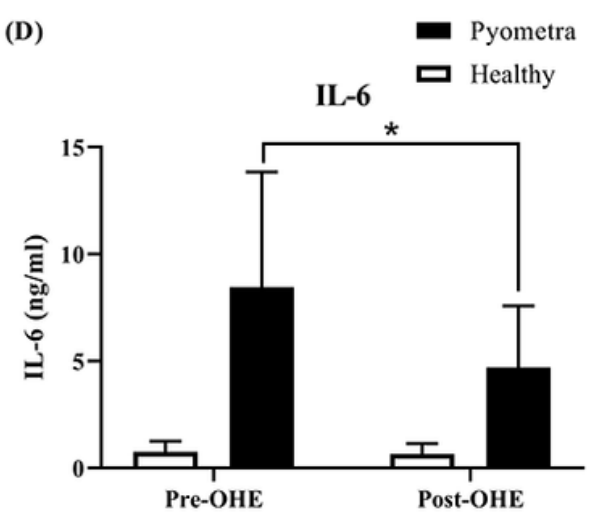

(B)

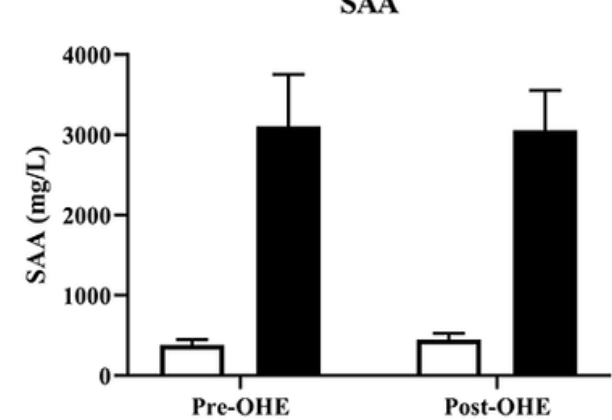

(E)

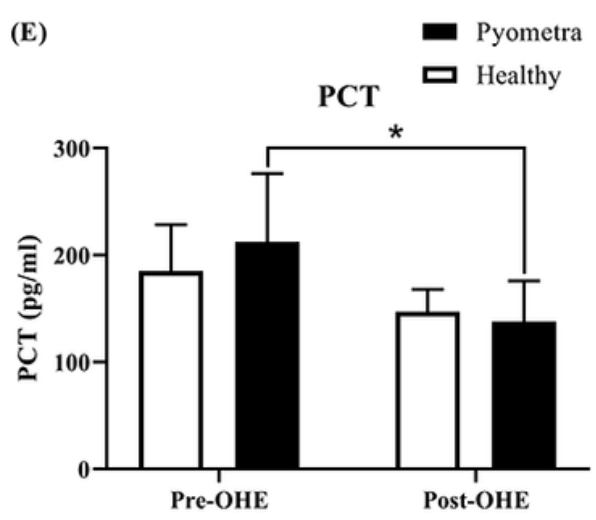

(C) cfDNA $\square$ Pyometra

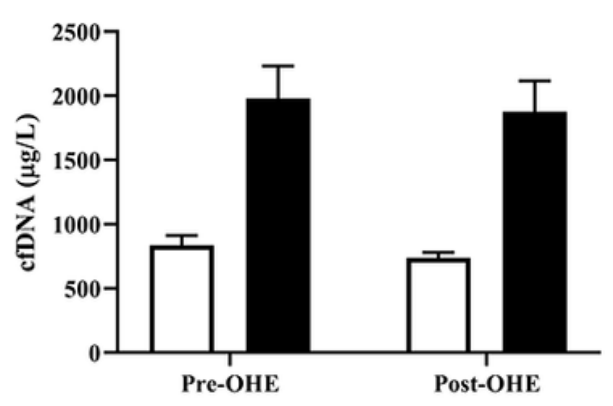

(F)
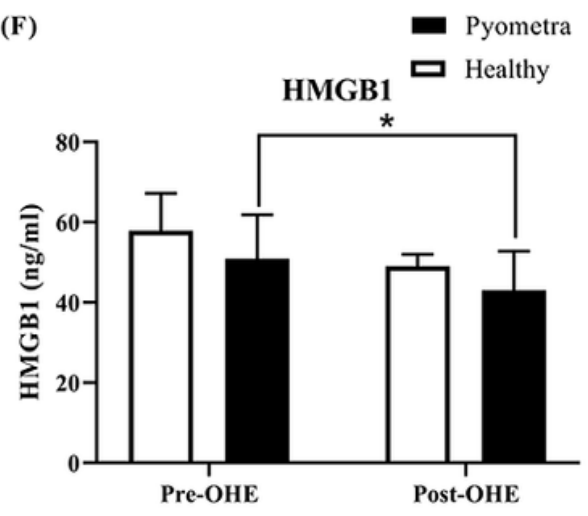

Figure 3

Plasma concentrations of inflammatory parameters in healthy controls and dogs with pyometra. Subjects were categorised as pre-ovariohysterectomy (OHE) and post-OHE. (A) C-reactive protein (CRP); (B) serum amyloid A (SAA); (C) cell-free DNA (cfDNA); (D) IL-6; (E) procalcitonin (PCT); and (F) high-mobility group box 1 (HMGB1). All data are presented as the mean \pm SD. *P $<0.05,{ }^{* *} \mathrm{P}<0.01$ between pre- and post-OHE dogs with pyometra. 